\title{
Article \\ Cryptocurrency Open Innovation Payment System: Comparative Analysis of Existing Cryptocurrencies
}

\author{
Valery Titov ${ }^{1}$, Mafura Uandykova ${ }^{2}$, Oleg Litvishko ${ }^{1}$, Tatyana Kalmykova ${ }^{1}$, Sergey Prosekov ${ }^{3, *}$ \\ and Tomonobu Senjyu ${ }^{4}$ (i) \\ 1 Institute of Mathematics, Information Systems and Digital Economy, Plekhanov Russian University of \\ Economics, 117997 Moscow, Russia; titov575@ya.ru (V.T.); oleh.litvishko@ya.ru (O.L.); \\ kalmikova989@ya.ru (T.K.) \\ 2 Department of Digital Engineering and Data Analysis, Narxoz University, Almaty 050035, Kazakhstan; \\ mafura.uandykova@ya.ru \\ 3 Department of Humanities, Financial University under the Government of the Russian Federation, \\ 125167 Moscow, Russia \\ 4 Department of Electrical and Electronics Engineering, University of the Ryukyus, Nishihara 903-0213, Japan; \\ b985542@tec.u-ryukyu.ac.jp \\ * Correspondence: ser.prosekov@ya.ru
}

Citation: Titov, V.; Uandykova, M.; Litvishko, O.; Kalmykova, T.;

Prosekov, S.; Senjyu, T.

Cryptocurrency Open Innovation

Payment System: Comparative

Analysis of Existing Cryptocurrencies

J. Open Innov. Technol. Mark. Complex.

2021, 7, 102. https://doi.org/

10.3390/joitmc7010102

Received: 28 January 2021

Accepted: 12 March 2021

Published: 19 March 2021

Publisher's Note: MDPI stays neutra with regard to jurisdictional claims in published maps and institutional affiliations.

Copyright: (C) 2021 by the authors Licensee MDPI, Basel, Switzerland. This article is an open access article distributed under the terms and conditions of the Creative Commons Attribution (CC BY) license (https:// creativecommons.org/licenses/by/ $4.0 /)$.

\begin{abstract}
This study was conducted to evaluate the implementation of an open innovation cryptocurrency financial system using a statistical approach. The data array reflects the actual speed of the cryptocurrency system, expressed in transactions per second (TPS), taken as the average annual speed. The article offers a comprehensive approach for choosing the optimal cryptocurrency financial system. The final analysis shows that the reasons for the adoption of the cryptocurrency financial system are practicality and convenience, as well as efficient transaction time, faster payment, and simplicity of the payment process. The impact of social factors, expected efforts, and conditions of assistance on the attitude to the cryptocurrency financial system were evaluated. In addition, social factors that have a significant impact on the implementation of the cryptocurrency financial system were identified.
\end{abstract}

Keywords: cryptocurrency; correlation analysis; velocity; bitcoin; EOS

\section{Introduction}

This study aimed to evaluate the implementation of an open innovation cryptocurrency financial system using a statistical approach. With a processing speed potential of 50,000 transactions per second, the cryptocurrency EOS (EOS) system is able to meet most of the needs for money transfers in the large global market.

The novelty of the paper is a comprehensive approach for choosing the optimal cryptocurrency financial system at the base of transaction speed. The paper fills the literature gap in finding of the optimal cryptocurrency financial system. This paper hypothesis is that the optimal cryptocurrency financial system is EOS.

Despite the fact that the definition of financial system often appears in numerous scientific studies and publications in the field of finance, attempts to accurately define this term face difficulties. The meaning of the financial system is revealed in different ways, based on the approaches to the study of this term. There are five main approaches:

1. The institutional one defines the financial system from the point of view of financial institutions and considers their functioning and relationships within the market;

2. The monetary one considers the financial system from the side of providing the real economy with money, that is, it reveals this concept as a mechanism for providing the real economy with money; 
3. The distributive one characterizes the financial system from the point of view of the functions of distribution and transformation of capital or from the point of view of the mechanism of redistribution of funds depending on their excess or shortage;

4. The functional one performs the function of a system that covers a network of financial markets, financial intermediaries, and other financial institutions that implement the financial plans of households, businesses, and public authorities; and

5. In the system approach the relationship between the elements of the financial system and their impact on the functioning of the financial sector and the economy as a whole is considered [1].

The development of cryptocurrencies as an analogue of traditional money required increasing the speed of transactions, controllability of circulation, and stability of the currency exchange rate. One of the most promising solutions to this problem may be the construction of cryptocurrency systems with centralized management and the main coin. A special feature of the Tether is its binding to the currency, which is a solution to the problem of the lack of internal value of cryptocurrencies. The EOS platform features an open source system with the ability to develop third-party applications for its practical application in the monetary turnover of different companies and partial centralization of the management system, which is based on a standardized technological equipment of twenty nodes, which, in turn, increase the stability of the system and simplify its scalability.

\section{Literature Review}

Many studies discussed whether global drivers of the cryptocurrency infrastructure adoption and future tendency. The existing market of payment systems and financial technologies is the main reference point for the development of crypto assets, since the number of non-cash payments and bank cards is constantly growing, therefore, the market where cryptocurrency wants to compete has a growing demand [2-5].

However, cryptocurrencies have a number of features that distinguish them from the usual fiat money and financial assets, and prevent the rapid introduction of digital currencies and cryptocurrency systems to the global financial market. The main advantages of digital currencies are the confidentiality and reliability of information transmitted within the system, and the freedom of transactions. This characteristic applies mostly to decentralized peer-to-peer networks with distributed management [6-8].

Other researchers discussed the actual speed of the cryptocurrency system, expressed in transactions per second (TPS), taken as the average annual speed [9-12]. Their main disadvantages are the high volatility, the difficulty of forecasting, the low throughput platforms, and scalability issues. However, all this makes it possible to use cryptocurrencies as a high-risk asset that is able to diversify the risk of the portfolio due to low correlation with the main market indicators. When analyzing the cryptocurrency market, the absolute market leader in terms of capitalization and average daily trading turnover was revealed the bitcoin with a market share of $67 \%$ at the beginning of 2020 and a share in the overall trading structure of about half of the market.

However, it is worth noting the tendency to weaken the leading positions of the cryptocurrency due to regular initial coin offering (ICO) and the release of new platforms to the market. This has a positive effect on competition within the market. The volatility of such an asset over the past three years is $12 \%$, which is six times higher than the same indicator for the market benchmark (S\&P500).

Many researchers study the implementation of an open innovation cryptocurrency financial system using a statistical approach $[3,4,10]$. Cryptocurrency financial systems are able to provide a high level of security due to the blockchain network; in addition, cryptocurrencies minimize the risks of loss or change of information in the system due to their decentralized nature. Here, one of the main advantages of cryptocurrency is distributed problem of regulation and monitoring by the state (Figure 1) [9]. 


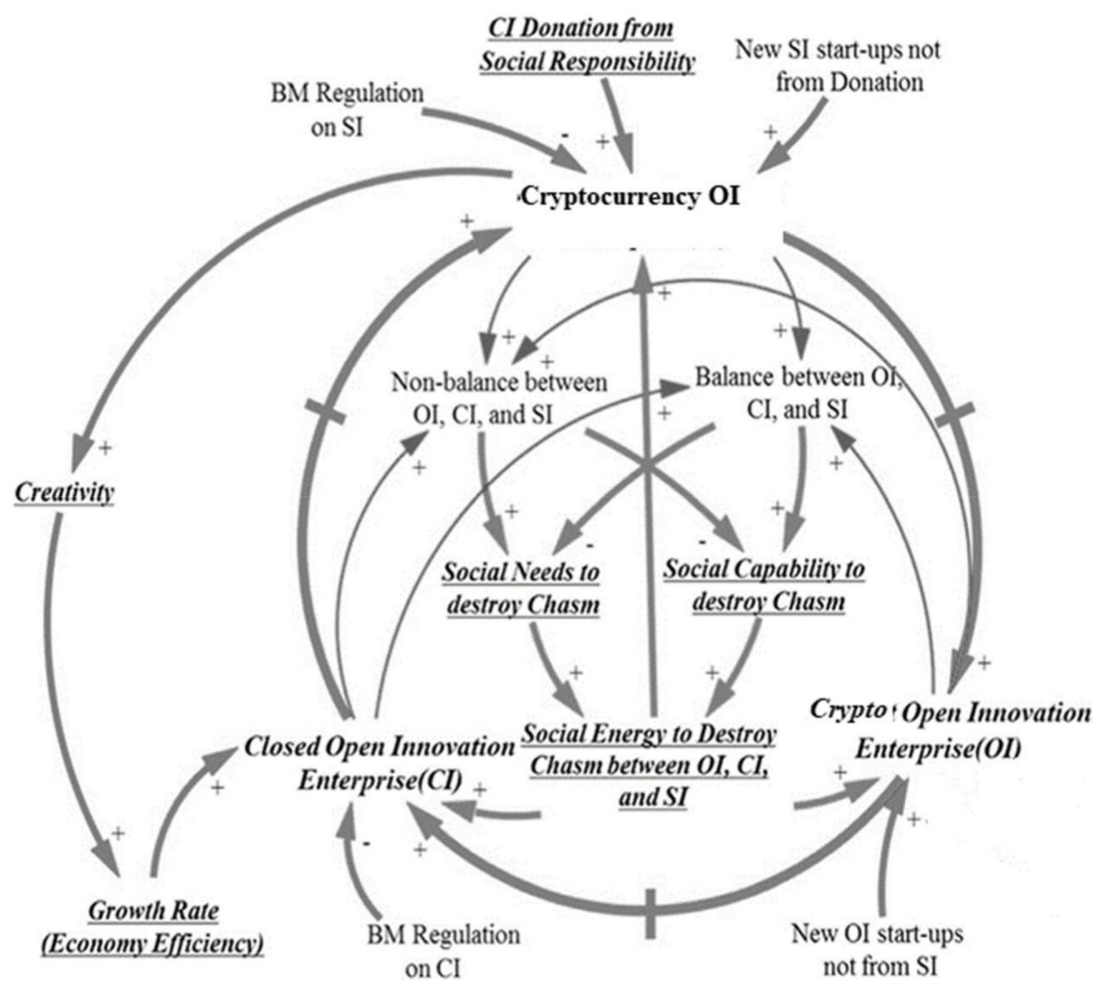

Figure 1. Open innovation dynamics. (Source: designed by authors on the base of the paper [13]).

The evolution of knowledge sharing processes and mechanisms best reflects the dynamics of open innovation. The dynamics described in the scientific literature can be divided into qualitative and quantitative ones. The mechanisms of integration of technology transfer projects into the programs of long-term development of the technology market, industries and complexes are considered the expressed specifics of the model $[10,11]$.

The Behrman-Wallender model is focused on the description of international knowledge exchange, localization of production. It is presented through seven stages: (1) Determination of the location and economic justification of the project; (2) selection of the IPO and technologies for localization; (3) development of the location plan on the land plot and determination of the necessary infrastructure; (4) construction of the plant and start-up of production; and (5) technologies. Furthermore, the description of the stages of the models are adopted by the author for the traditional in economics and practical vocabulary [9]: (6) adaptation of personnel and debugging of production; and (7) building communication, contract base with the management of localized production. The specifics and scientific contribution of the model determine the identification and description of the stages of the organization of interstate technological transfer in production localization projects [5].

The Dahlman-Westphal model in terms of determining the subjects and objects of the knowledge movement (OIS), relative to the nine stages of technological transfer [9]. By the way, the central banks and financial ministries are required to monitor the state of monetary turnover in the country in order to conduct an effective monetary policy, that is, the state needs institutions responsible for these procedures. On the other hand, potential cryptocurrency users, citizens, are interested in data privacy and decentralized management (Table 1). However, both centralized and decentralized management have a number of advantages and disadvantages [10-13]. 
Table 1. Characteristics of centralized and decentralized cryptocurrency systems.

\begin{tabular}{ccc}
\hline Characteristics & Decentralized System & Centralized System \\
\hline Transaction confirmation & It takes place using power technology & $\begin{array}{c}\text { Controls the system management, which } \\
\text { is an independent party [14] }\end{array}$ \\
\hline Scalability & $\begin{array}{c}\text { Problems of bandwidth expansion, frequent } \\
\text { emission limitations }\end{array}$ & $\begin{array}{c}\text { High throughput and expansion } \\
\text { capabilities of the system [15] }\end{array}$ \\
\hline Stability & $\begin{array}{c}\text { The heterogeneity of the technical equipment } \\
\text { of the system participants makes it } \\
\text { unpredictable and unstable }\end{array}$ & $\begin{array}{c}\text { Standardized control system hardware } \\
\text { and software improves the stability and } \\
\text { speed of the system }\end{array}$ \\
\hline Risk of Attack $51 \%$ & $\begin{array}{c}\text { The smaller the system, the greater the } \\
\text { possibility of capturing control by a group of } \\
\text { miners with a share greater than 51\% [16] }\end{array}$ & NA \\
\hline Privacy & No need for personal data [17] & NA \\
\hline
\end{tabular}

This is one of the main contradictions of cryptocurrencies: the openness of the system, its supranationality and a high level of automation imply the absence of centralized control over its issue and movement of digital currency from any state [18-22].

\section{Methods}

The methods is to evaluate the capabilities and potential of cryptocurrencies in the field of providing the economy with a means of payment and a payment system. As existing analogues, we will consider the current payment systems that are among the leaders in their segments: VISA, which represents the payment card segment, and PayPal, which is a representative of the electronic payment service. As competitors, we will take the EOS system as the system with the greatest scalability potential and Bitcoin as the most popular cryptocurrency. The cryptocurrency payment chain via Smart Contract is the process with many points (Figure 2).

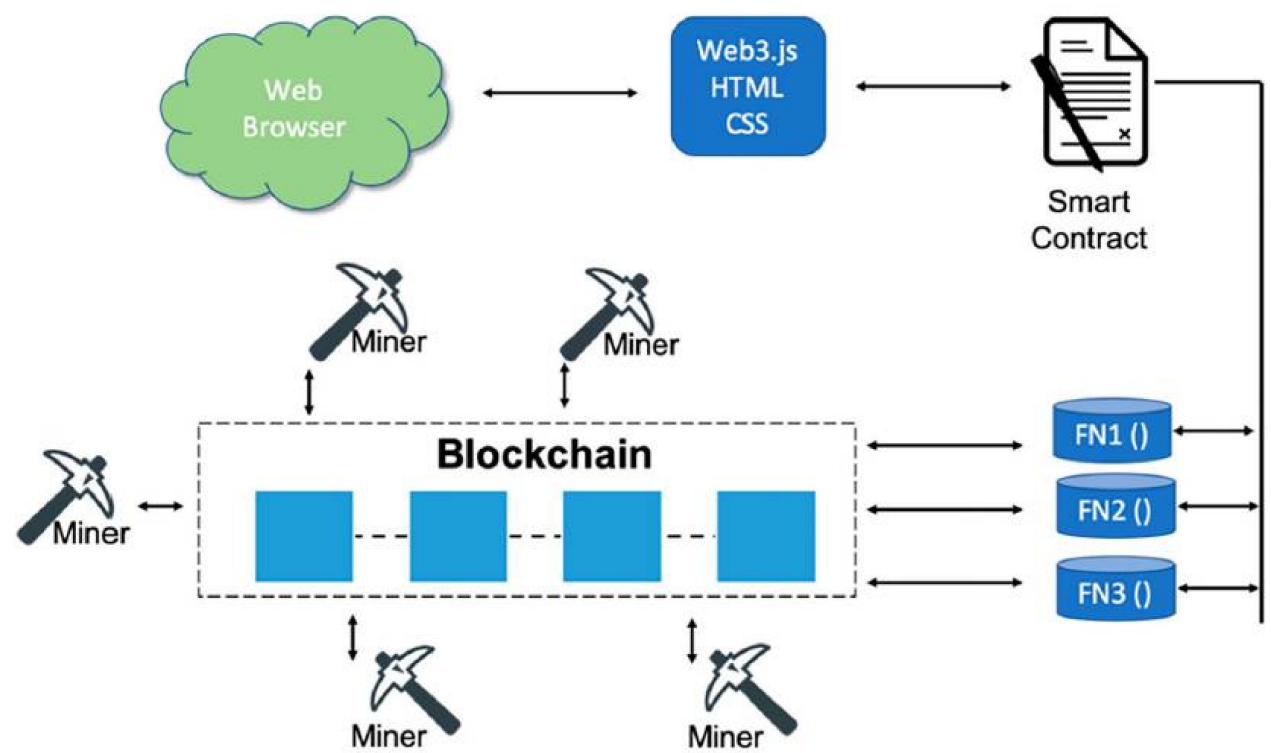

Figure 2. Cryptocurrency payment chain via Smart Contract. Source: Authors.

The data presented in the histogram below reflects the actual speed of the analyzed systems, expressed in transactions per second (tps), taken as the average annual speed for 2019, as well as their potential in speed. This comparison is necessary because, if the cryptocurrency payment system becomes the only global payment system, it must digest the market capacity and ensure stability at speeds equal to the current market leaders [23-25]. The study based on 
Python 3.6.10 software to identify the strength and direction of the relationship between the speeds of crypto platforms. The linear correlation coefficient (1) was used, too:

$$
r_{X Y}=\frac{\operatorname{cov}_{X Y}}{\sigma_{X} \sigma_{Y}}=\frac{\sum(X-\bar{X})(Y-\bar{Y})}{\sqrt{\sum(X-\bar{X})^{2} \sum(Y-\bar{Y})^{2}}}
$$

Using this indicator, it will be revealed how much influence the transit speed has. After calculating the correlation indicators, a regression analysis of the relationships of those indicators with the highest correlation was performed to confirm the result and draw conclusions about the significance of the constructed model and its quality (2). Using the linear regression model, it is possible to identify the degree of relationship between the dependent variable $Y$ and the independent value of $X$.

The values of the dependent variable are indicators of factors related to the transaction speed of payment systems, and the values of the variable $X$ are indicators of the cryptocurrency platform industry:

$$
Y_{i}=a_{0}+a_{1} X_{i}+\varepsilon_{i}
$$

After constructing the model and studying the quality of the relationship between the features, using the Fisher criterion at the significance level of 0.05 (3), it is possible to conclude about the significance of the research results and their significance in forming General conclusions. The quality of the linear regression model will be evaluated using the average approximation error (4), which allows you to evaluate the resulting model and the prospect of using the results in drawing conclusions [26-30]:

$$
\begin{gathered}
F=\frac{R^{2} /(k-1)}{\left(1-R^{2}\right) /(n-k)} \sim F(k-1 ; n-k) \\
A=\frac{1}{n} \sum \frac{\left|y_{i}-\bar{y}_{i}\right|}{y_{i}} * 100 \%
\end{gathered}
$$

As for the next approach, monetary, the problem of many cryptocurrencies is its volatility and unpredictability, since there is no reliable Foundation for justifying their prices. This problem can be solved by stablecoins is a stable digital currency. A pioneer in this segment is the tether crypto asset. Its value is tied to the dollar and secured by the company's reserves of US dollars stored in bank accounts [31-33].

From the data presented above, it can be seen those two platforms with different characteristics: decentralized Bitcoin and EOS with centralized management-have completely different potential system speeds (Figure 3). The fact is that the speed of a decentralized system is limited by the speed of the slowest participant in the system, while EOS limits the productive capacity of the management system. According to the developers of this system, it is difficult to determine the exact potential for the speed of transactions in EOS, but the project is easily scalable due to the multithreading of the blockchain, standardized control blocks, and open code for developing third-party applications [26-28].

One of the main problems of such a currency is its instability, which can be solved by linking its value to other assets, or by forming cryptocurrencies as obligations of large organizations, perhaps even supranational ones.

Problems related to the replacement of banking activities can be solved by introducing and further developing smart contracts in the financial system, which will automatically facilitate the redistribution of capital, but this will require centralized management and personal data to identify network users [29-31]. 


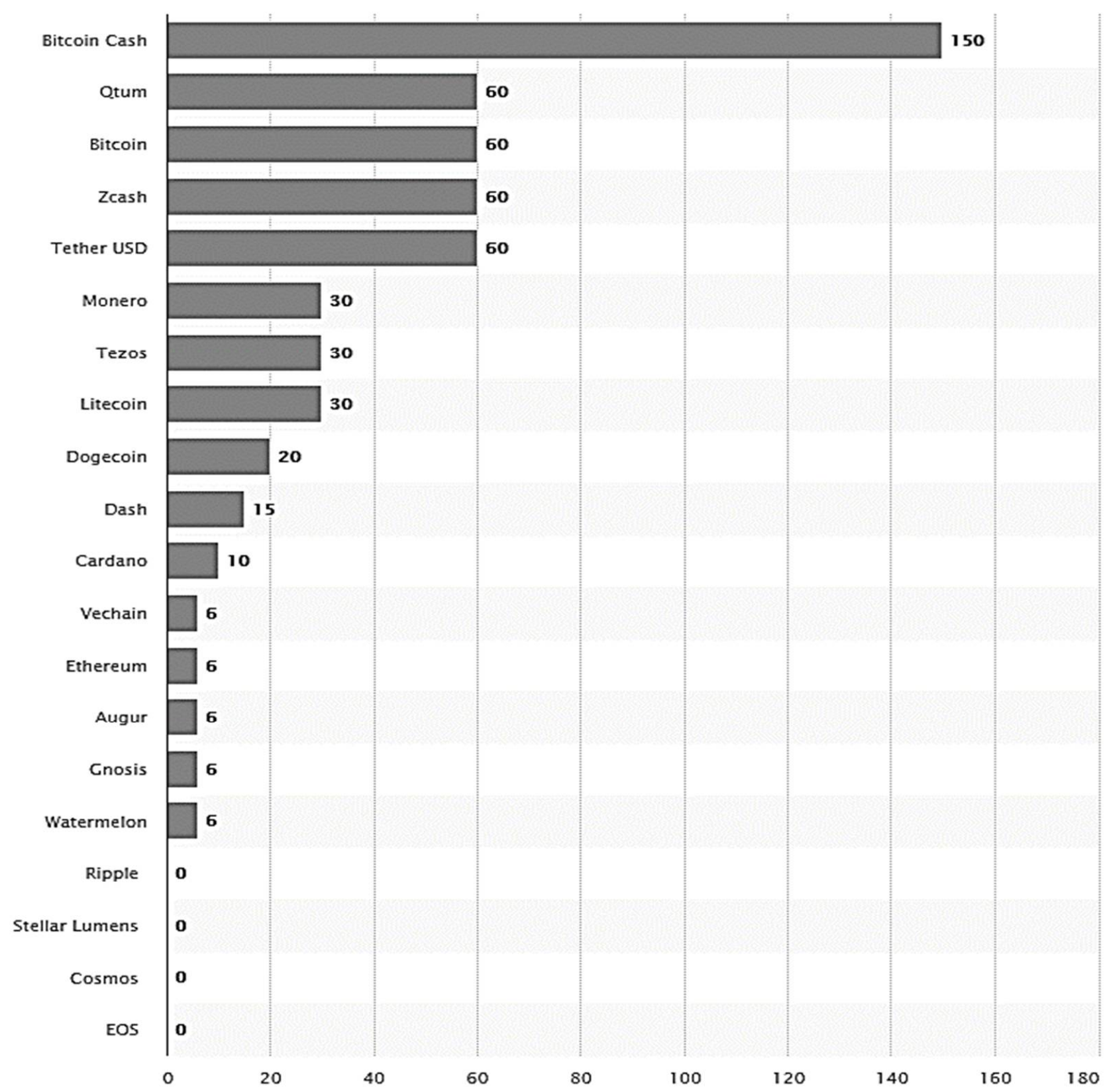

Figure 3. Transaction speed at cryptoplatforms, min. Source: Blockchain.com (accessed on 18 March 2021), authors.

\section{Results}

Since cryptocurrencies do not have proper regulation and recognition as generally accepted money, their widespread use as a means of circulation can entail significant economic and financial risks like previous researchers wrote before [34-36].

However, the disadvantages of such a currency are more critical: the consolidation of risks in one currency can be a potential threat to the global economy. The next one is equal pricing policy, since international companies will have to set the same prices. With the same prices and different living standards in different countries, the disparity in the wealth of the world's population will increase (Table 2). 
Table 2. F-test summary.

\begin{tabular}{|c|c|}
\hline Regression Model & F \\
\hline Bitcoin Cash & 6.47 \\
\hline Qtum & 2.64 \\
\hline Bitcoin & 1.36 \\
\hline Zcash & 3.06 \\
\hline Tether & 2.68 \\
\hline Monero & 0.005 \\
\hline Tezos & 5.48 \\
\hline Litecoin & 3.06 \\
\hline Dogecoin & 0.82 \\
\hline Dash & 1.97 \\
\hline Cardano & 3.70 \\
\hline Vechain & 0.01 \\
\hline Ethereum & 1.43 \\
\hline Augur & 0.04 \\
\hline Gnosis & 0.93 \\
\hline Watermelon & 0.97 \\
\hline Ripple & 1.70 \\
\hline Stellar Lumens & 0.51 \\
\hline Cosmos & 0.43 \\
\hline EOS & 0.14 \\
\hline Visa & 4.33 \\
\hline
\end{tabular}

Source: Blockchain.com (accessed on 18 March 2021), authors.

Unlike bitcoin and altcoins, Tether has much lower volatility, which increases the prospect of using stablecoins as an alternative to fiat money. However, if we are talking about the complete replacement of existing traditional money with digital currencies, another asset will be needed to provide them. This can be a precious metal, or an obligation on the part of the state on the principle of the existence of money. Another obstacle to this development may be the risks associated with the need for such a system in the existence of a single currency. The advantages of the single currency include ease of use for international payments. The public will not need to search for exchange offices and there will be no costs associated with currency exchange. International transactions will also be significantly simplified, where there will be no need for constant adjustments to the terms of the agreement regarding current exchange rates. The third advantage is to strengthen and multiply economic and financial ties in the international arena.

If we consider digital currencies as a financial asset, then they will face a very large number of macro- and micro-economic factors that affect their quotes on the market. It is necessary to evaluate this effect by means of correlation and regression analyses. However, the risks faced by cryptocurrencies are specific, since this asset has no analogues in the market. The chart below shows the quotes of the main indices - S\&P500 and the Dow Jones index (DJI), also it included Moscow exchange index (IMOEX). The analyzed period is three years: From 1 March 2017 to 1 March 2020 (Figure 4). 


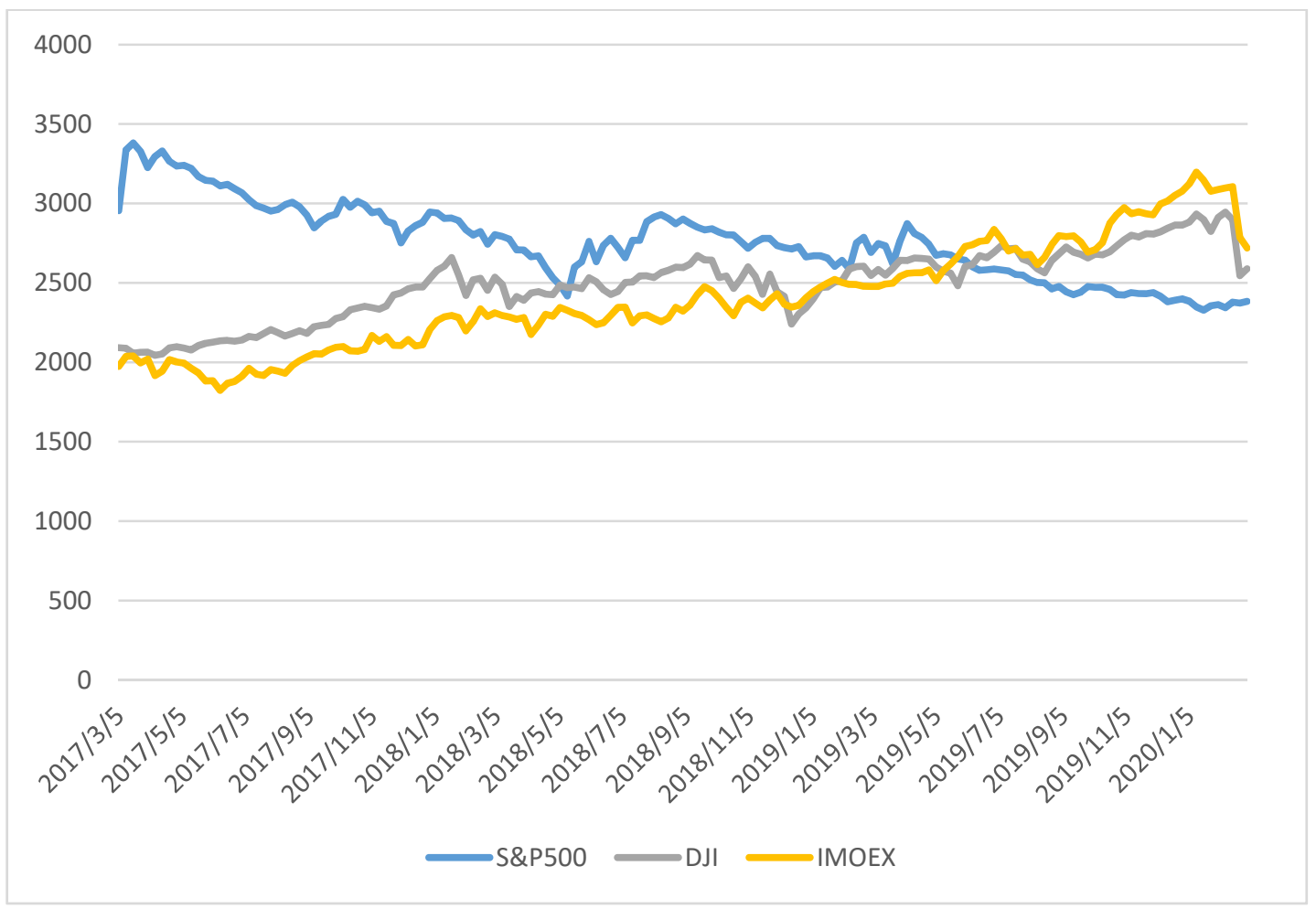

Figure 4. Dynamics of stock indices. Source: Blockchain.com (accessed on 18 March 2021), authors.

The data shown on the chart has a similar value that differs from their absolute values, for a visual comparison of indices and cryptocurrencies. This allows you to evaluate the correlation and trends that occur in the markets. The chart shows that the IMOEX, DJI indices and Bitcoin have a direct relationship and an inverse relationship with the S\&P500 index. This indicates that these financial instruments are influenced by the same market factors. Consequently, the estimation and forecasting of their indicators will be based on standard estimation methods. As for the cryptocurrency, there is no correlation between the indicators. It is also worth noting the high volatility of the digital currency, relative to market benchmarks over the past three years. The volatility analysis is based on daily returns. It was used correlation of natural logarithms of daily returns. The time interval is daily for the period of last three years. The regression analysis time interval is daily for the period of last five years (Tables 3 and 4).

The calculated data shows that there is a strong correlation between the IMOEX, S\&P, and DJI indices with a correlation coefficient greater than 0.84 in each comparison. The dependence of the cryptocurrency on these indices can be considered insignificant for the purposes of the study, therefore, the prediction of Bitcoin prices will differ significantly methodically from the schemes for analyzing these indices. The lack of relationships between indicators can be used to diversify portfolio risks, which is one of the main factors in using this asset for investment purposes. Crypto assets can be classified as high-risk, however, unlike financial assets with inherent risks, cryptocurrency does not provide a flow of payments in the form of dividends.

To assess the degree of risk of an asset, it is necessary to compare the volatility of cryptocurrency prices and benchmarks-market indices. The table below shows the average relative and absolute changes in prices for these financial instruments, calculated based on the average standard deviations of prices and returns. 
Table 3. Correlation analysis of daily returns.

\begin{tabular}{ccccc}
\hline & Bitcoin & S\&P500 & DJI & IMOEX \\
\hline Bitcoin & 1 & & & \\
\hline S\&P500 & 0.53008 & 1 & 1 & \\
\hline DJI & 0.607055 & 0.84014 & 0.911365 & 1 \\
\hline IMOEX & 0.439451 & 0.87806 & & \\
\hline
\end{tabular}

Source: Authors calculation.

Table 4. Regression summary.

\begin{tabular}{cccc}
\hline Explained Variables & $\begin{array}{c}\text { Number of Transactions Added } \\
\text { to the Mempool per Second }\end{array}$ & $\begin{array}{c}\text { Number of Terahashes per } \\
\text { Second in the Last 24 h }\end{array}$ & $\begin{array}{c}\text { Average Time for Which a Transaction } \\
\text { Including in the Extracted Block and } \\
\text { the Public Register }\end{array}$ \\
\hline Bitcoin cash & 0.03 & 0.02 & -0.05 \\
\hline Bitcoin & 0.02 & 0.02 & -0.01 \\
\hline Ethereum & 0.16 & 0.23 & -0.14 \\
\hline Ripple & 0.03 & 0.04 & -0.02 \\
\hline Bitcoin & 0.02 & 0.04 & -0.06 \\
\hline Stellar & 0.03 & 0.07 & -0.05 \\
\hline Litecoin & 0.08 & 0.16 & -0.08 \\
\hline Monero & 0.01 & 0.08 & -0.07 \\
\hline IOTA & 0.01 & 0.05 & -0.03 \\
\hline Dash & 0.05 & 0.08 & -0.05 \\
\hline Cosmos & 0.06 & 0.05 & -0.03 \\
\hline EOS & 0.01 & 0.01 & -0.01 \\
\hline Significance level & 0.05 & 0.05 & 0.05 \\
\hline Observations & 1.825 & 1.825 & 1.825 \\
\hline R2 & 0.914 & 0.828 & 0.747 \\
\hline Adjusted R2 & 0.912 & 0.829 & 0.748 \\
\hline
\end{tabular}

Source: Authors calculation.

\section{Discussion: Cryptocracy Open Innovation}

Accordingly, if there is a positive news background, for example, about innovations in the cryptosphere or the legalization of digital currencies, the exchange rate of such assets will actively grow, and if the opposite situation is unfavorable news, the market will react in the opposite way [37-39].

The market played back all the strong drops in bitcoin prices and successfully compensated for the price drop that formed in 2018 and returned to the previous level. The rate of little-known cryptocurrencies may fluctuate for no direct reason at all. Sometimes a fall or rise in the exchange rate of bitcoin or other major currency is enough for it to fall or grow. Compared to common financial assets, the volatility of cryptocurrencies is much greater. The main reason for such a large spread in prices for crypto assets is the complexity of forecasting and analyzing cryptocurrencies: people do not know what to expect from it [40-43]. due to:

The volatility of the studied cryptocurrencies has been greatly reduced in recent years

1. Increasing state acceptance and regulation. For example, the dollar is supported and provided by financial institutions of a large number of developed countries with stable economies, as well as a very large demand for this currency in international economic and financial relations [44,45]. 
2. The possibility of linking the value of cryptocurrencies to specific assets, which ensures the reliability of the cryptocurrency, for example, the cost of electricity. This means that there are no real specific performance indicators that confirm the intrinsic value of the cryptocurrency. For example, the internal value of shares is determined by analyzing the financial condition of the issuer and its performance indicators (liquidity, profitability, property value, etc.) [46,47].

3. The human factor. In the absence of oscillators and other indicators on the stock exchange in the crypto sector, investors tend to make trading mistakes, which negatively affects the stability of supply and demand and, accordingly, the cryptocurrency exchange rate.

These factors of cryptocurrency volatility do not allow us to consider them as potential money, but they can be distinguished as a specific financial asset with high risk indicators and potential profitability, which can positively affect the successful formation of a diversified portfolio. The solution to this problem may be the emergence and expansion of the regulatory framework for the definition and circulation of cryptocurrencies [48,49].

If we consider the cryptocurrency from the other side-as a potential common currency, a means of redistribution and payment, then it faces legal risks, which, in turn, pose new threats to the financial system [50-53].

The uncertainty of legal regulation is one of the main problems of many countries, including Russia, which hinders the development and implementation of cryptocurrencies in the financial system. In addition, given the fact that the digital currency market, thanks to self-regulation and self-development, begins to function without the participation of state control, this fact can cause potential damage to both the participants of the system and the world economies [54-59].

As a result, we can conclude that the financial system in the modern world economy is very multifaceted and includes a very large system that unites institutions and mechanisms that ensure the functioning of the financial sector and the economy as a whole [60-64]. At this stage, crypto assets can be characterized as potential investments with high risk, but also with the possibility of obtaining a large income due to the strong volatility of quotations [65-68].

However, in order to become something more, to become a full-fledged participant in the financial system, cryptocurrencies must perform not only the role of money, but also distribution mechanisms that ensure the flow of money into the economy. The most significant disadvantages of cryptocurrencies are their instability and legal instability in many countries [69].

\section{Conclusions}

In this article, a study was conducted of the risks and prospects of cryptocurrencies in the global financial system. It was studied the theoretical aspects of the concept of cryptocurrency, the stages of development of the term itself and the technologies associated with it, the analysis of the current market of digital currencies, a comparative analysis of existing cryptocurrencies with fiat money, assets, and presents data on competition in the market.

Based on the results of the study, it can be concluded that it is difficult to define the term cryptocurrency system due to the insufficient regulatory framework for this sector in most developed countries. It is possible to present the most accurate description of this phenomenon thanks to the science of cryptography, which studies ways to encrypt information, transmit and decrypt data. Thus, it was used in the 90s of the last century to create a blockchain technology based on the construction of a chain of interconnected encrypted data, which found its application in registering transactions within cryptocurrency systems.

Now cryptocurrencies are becoming more common: Develop and expand existing and new systems and platforms, after the fall of 2018 is actively growing the market capitalization increased average daily trading volume and increased market capacity. 
Based on the analysis, it was found that the EOS platform is currently able to compete with one of the leading companies in the field of payment systems is Visa. With a processing speed of 50,000 transactions per second, the EOS platform is able to meet most of the money transfer needs of the world's large market. In our opinion, a promising cryptocurrency system should include the above features for using the digital currency as the main means of payment, but use an asset other than the currency, such as gold, as a stability element, or create conditions for the Issuer's obligations to appear when issuing the digital currency.

In such a system, the issuer regulator may be a certain large independent company, possibly supranational, to ensure the safety of data and partial confidentiality of network users. To ensure the preservation of tax and credit mechanisms, smart contracts should be used, which, thanks to the openness of the EOS system code, will be able to adapt to any organization and, thus, ensure stable automated monetary circulation between counterparties.

As a result, the existing cryptocurrency financial system was evaluated. With a processing speed potential of 50,000 transactions per second, the EOS-based cryptocurrency system is able to meet most of the needs for money transfers in the large global market.

Author Contributions: Conceptualization: V.T.; data curation: V.T.; formal analysis: O.L.; funding acquisition: O.L.; investigation: T.K.; methodology: S.P.; project administration: S.P.; resources: S.P.; software: T.S.; supervision: T.S.; validation: T.S.; visualization: S.P.; writing-original draft: V.T. and M.U.; writing - review and editing: S.P. and M.U. All authors have read and agreed to the published version of the manuscript.

Funding: This research received no external funding.

Data Availability Statement: Data sharing not applicable.

Conflicts of Interest: The authors declare no conflict of interest.

\section{References}

1. Vejačka, M. Basic Aspects of Cryptocurrencies. J. Econ. Bus. Financ. 2014, 2, 75-83.

2. Saiedi, E.; Bronström, A.; Ruiz, F. Global drivers of the cryptocurrency infrastructure adoption. Small Bus. Econ. 2020. [CrossRef]

3. Batrancea, L.; Batrancea, I.; Moscviciov, A. The analysis of entity's liquidity-A means of evaluating cash flow. Int. J. Financ. Econ. 2009, 9, 92-98.

4. Giudici, G.; Milne, A.; Vinogradov, D. Cryptocurrencies: Market analysis and perspectives. J. Ind. Bus. Econ. 2019, 47, 1-18. [CrossRef]

5. Uematsu, Y.; Tanaka, S. High-dimensional Macroeconomic Forecasting and Variable Selection via Penalized Regression. Econ. J. 2017. [CrossRef]

6. Tinbergen, J. Shaping the World Economy; Suggestions for an International Economic Policy; Twentieth Century Fund: New York, NY, USA, 1962; p. 113.

7. Tasca, P.; Hayes, A.; Liu, S. The evolution of the Bitcoin economy: Extracting and analyzing the network of payment relationships. J. Risk Financ. 2018, 19, 94-126. [CrossRef]

8. Swan, M. Blockchain: Blueprint for a New Economy; O’Reilly Media, Inc.: Newton, MA, USA, 2015; p. 23.

9. Singh Maini, S.; Govinda, K. Stock Market Prediction using Data Mining Techniques. In Proceedings of the IEEE 2017 International Conference on Intelligent Sustainable Systems (ICISS 2017), Tirupur, India, 7-8 December 2017.

10. Silva, J.S.; Tenreyro, S. The log of gravity. Rev. Econ. Stat. 2006, 88, 641-658. [CrossRef]

11. Shahrivari, S.; Jalili, S. Beyond Batch Processing: Towards Real-Time and Streaming Big Data. Computers 2014, 3, 117. [CrossRef]

12. Remy, C.; Rym, B.; Matthieu, L. Tracking Bitcoin users activity using community detection on a network of weak signals. In Proceedings of the 6th International workshop on complex networks and their applications, Lyon, France, 29 November1 December 2017; Springer: Berlin/Heidelberg, Germany, 2017; pp. 166-177.

13. Yun, J.J.; Won, D.; Park, K. Dynamics from open innovation to evolutionary change. J. Open Innov. Technol. Mark. Complex. 2016, 2, 7-22. [CrossRef]

14. Reid, F.; Harrigan, M. An Analysis of Anonymity in the Bitcoin System. Security and Privacy in Social Networks; Springer: Berlin/Heidelberg, Germany, 2013; pp. 197-223.

15. Puri, V. Decrypting Bitcoin Prices and Adoption Rates Using Google Search. CMC Senior Theses, Claremont McKenna College, Claremont, CA, USA, 2016. Paper 1418. p. 27. Available online: http://scholarship.claremont.edu/cmc_theses (accessed on 12 March 2021).

16. Neudecker, T.; Hartenstein, H. Could network information facilitate address clustering in Bitcoin? In Proceedings of the 21st International Conference on Financial Cryptography and Data Security, Sliema, Malta, 3-7 April 2017; Springer: Cham, Switzerland, 2017; pp. 155-169. 
17. Hedge, M.S.; Krishna, G.; Srinath, R. An Ensemble Stock Predictor and Recommender System. In Proceedings of the IEEE 2018 International Conference on Advances in Computing, Communications and Informatics (ICACCI 2018), Bangalore, India, 19-22 September 2018.

18. Manning, C.D.; Raghavan, P.; Schütze, H. Introduction to Information Retrieval; Cambridge University Press: New York, NY, USA, 2008; p. 123.

19. Lohrmann, C.; Luukka, P. Classification of intraday S\&P500 returns with a Random Forest. Int. J. Forecast. 2018, 35. [CrossRef]

20. Lischke, M.; Fabian, B. Analyzing the Bitcoin network: The first four years. Future Internet 2016, 8, 7. [CrossRef]

21. Li, J.; Cheng, K.; Wang, S.; Morstatter, F.; Trevino, R.P.; Tang, J.; Liu, H. Feature Selection: A Data Perspective. arXiv 2016, arXiv:1601.07996. [CrossRef]

22. Lewer, J.J.; Van den Berg, H. A gravity model of immigration. Econ. Lett. 2008, 99, 164-167. [CrossRef]

23. Lahmiri, S.; Bekiros, S. Cryptocurrency forecasting with deep learning chaotic neural networks. Chaos Solitons Fractals 2019, 118, 35-40. [CrossRef]

24. Kroll, J.A.; Davey, I.C.; Felten, E.W. The economics of Bitcoin mining, or Bitcoin in the presence of adversaries. In Proceedings of the 12th Workshop on the Economics of Information Security (WEIS 2013), Washington, DC, USA, 11-12 June 2013 ; p. 11.

25. Kristoufek, L. What Are the Main Drivers of the Bitcoin Price? Evidence from Wavelet Coherence Analysis. PLoS ONE 2015, 10, e0123923. [CrossRef]

26. Kristoufek, L. BitCoin meets Google Trends and Wikipedia: Quantifying the relationship between phenomena of the Internet era. Sci. Rep. 2013, 3, 3415. [CrossRef] [PubMed]

27. Krauss, C.; Do, X.A.; Huck, N. Deep neural networks, gradient-boosted trees, random forests: Statistical arbitrage on the S\&P. Eur. J. Oper. Res. 2017, 259. [CrossRef]

28. Krause, M. Bitcoin: Implications for the Developing World. CMC Senior Theses, Claremont McKenna College, Claremont, CA, USA, 2016. Paper 1261. p. 75.

29. Koshy, D.; Koshy, P.; McDaniel, P. An analysis of anonymity in Bitcoin using p2p network traffic. In Proceedings of the 18th International Conference on Financial Cryptography and Data Security, Christ Church, Barbados, 3-7 March 2014; Springer: Berlin/Heidelberg, Germany, 2014; pp. 469-485.

30. Kohavi, R.; John, G. Wrappers for feature selection. Artif. Intell. 1997, 97, 273-324. [CrossRef]

31. Kenji, K.; Rendell, L. A practical approach to feature selection. In Proceedings of the 9th International Workshop on Machine Learning, Aberdeen, UK, 1-3 July 1992; pp. 368-377.

32. Kenda, K.; Kažič, B.; Novak, E.; Mladenić, D. Streaming Data Fusion for the Internet of Things. Sensors 2019, 19, 1955. [CrossRef] [PubMed]

33. Kang, Q.; Zhou, H.; Kang, Y. An Asynchronous Advantage Actor-Critic Reinforcement Learning Method for Stock Selection and Portfolio Management. In Proceedings of the 2nd International Conference on Big Data Research, Seattle, WA, USA, 10-13 December 2018; pp. 141-145.

34. Jiao, Y.; Jakubowicz, J. Predicting Stock Movement Direction with Machine Learning: An Extensive Study on S\&P 500 Stocks. In Proceedings of the 2017 IEEE International Conference on Big Data (IEEE BigData 2017), Boston, MA, USA, 11-14 December 2017.

35. Guo, T.; Antulov-Fantulin, N. Predicting short-term Bitcoin price fluctuations from buy and sell orders. arXiv 2018.

36. Goldberger, A.S. The Interpretation and Estimation of Cobb-Douglas Functions. Econometrica 1968, 36, 464. [CrossRef]

37. An, J.; Mikhaylov, A. Russian energy projects in South Africa. J. Energy South. Afr. 2020, 31, 58-64. [CrossRef]

38. An, J.; Mikhaylov, A.; Richter, U.H. Trade war effects: Evidence from sectors of energy and resources in Africa. Heliyon 2020, 6, e05693. [CrossRef] [PubMed]

39. Denisova, V.; Mikhaylov, A.; Lopatin, E. Blockchain infrastructure and growth of global power consumption. Int. J. Energy Econ. Policy 2019, 9, 22-29. [CrossRef]

40. Dooyum, U.D.; Mikhaylov, A.; Varyash, I. Energy security concept in Russia and South Korea. Int. J. Energy Econ. Policy 2020, 10, 102-107. [CrossRef]

41. Lee, M.; Yun, J.J.; Pyka, A.; Won, D.; Kodama, F.; Schiuma, G.; Park, H.; Jeon, J.; Park, K.; Jung, K.; et al. How to Respond to the Fourth Industrial Revolution, or the Second Information Technology Revolution? Dynamic New Combinations between Technology, Market, and Society through Open Innovation. J. Open Innov. Technol. Mark. Complex. 2018, 4, 21. [CrossRef]

42. Yun, J.J.; Liu, Z. Micro- and Macro-Dynamics of Open Innovation with a Quadruple-Helix Model. Sustainability 2019, 11, 3301. [CrossRef]

43. Yun, J.J.; Won, D.; Park, K. Entrepreneurial cyclical dynamics of open innovation. J. Evol. Econ. 2018, 28, 1151-1174. [CrossRef]

44. Wagner, R. The Invention of Culture; University of Chicago Press: Chicago, IL, USA, 2016.

45. Swidler, A. Culture in Action: Symbols and Strategies. Am. Sociol. Rev. 1986, 51, 273. [CrossRef]

46. Bhabha, H.K. The Location of Culture; Routledge: Abingdon, UK, 2012.

47. Grant, A.M.; Mayer, D.M. Good soldiers and good actors: Prosocial and impression management motives as interactive pre-dictors of affiliative citizenship behaviors. J. Appl. Psychol. 2009, 94, 900-912. [CrossRef]

48. Marion, T.; Fixson, S. The Innovation Navigator: Transforming Your Organization in the Era of Digital Design and Collaborative Culture; University of Toronto Press: Toronto, ON, Canada, 2018.

49. Coyle, D. The Culture Code: The Secrets of Highly Successful Groups; Bantam: New York, NY, USA, 2018. 
50. Murphy, P.J.; Cooke, R.A.; Lopez, Y. Firm culture and performance: Intensity's effects and limits. Manag. Decis. 2013, 51, 661-679. [CrossRef]

51. Hofstede, G. Culture's Consequences: Comparing Values, Behaviors, Institutions, and Organizations across Nations; Sage Publications: Thousand Oaks, CA, USA, 2001.

52. O'Rilly, C.; Chatman, J. Culture as social control: Corporations, culture, and commitment. Res. Organ. Behav. 1996, 18, 157-200.

53. Hope, O.K. Firm-level disclosures and the relative roles of culture and legal origin. J. Int. Financ. Manag. Account. 2003, 14, 218-248. [CrossRef]

54. Mello, J.E.; Stank, T.P. Linking firm culture and orientation to supply chain success. Int. J. Phys. Distrib. Logist. Manag. 2005, 35, 542-554. [CrossRef]

55. Galbreath, J. Drivers of Corporate Social Responsibility: The Role of Formal Strategic Planning and Firm Culture. Br. J. Manag. 2010, 21, 511-525. [CrossRef]

56. Ouchi, W.G.; Wilkins, A.L. Organizational culture. Annu. Rev. Sociol. 1985, 11, 457-483. [CrossRef]

57. Hartog, D.N.; Verburg, R.M. High performance work systems, organisational culture and firm effectiveness. Hum. Resour. Manag. J. 2004, 14, 55-78. [CrossRef]

58. Gura, D.; Mikhaylov, A.; Glushkov, S.; Zaikov, M.; Shaikh, Z.A. Model for estimating power dissipation along the interconnect length in single on-chip topology. Evol. Intell. 2020, s12065. [CrossRef]

59. Mikhaylov, A. Pricing in Oil Market and Using Probit Model for Analysis of Stock Market Effects. Int. J. Energy Econ. Policy 2018, 8, 69-73.

60. Mikhaylov, A. Volatility Spillover Effect between Stock and Exchange Rate in Oil Exporting Countries. Int. J. Energy Econ. Policy 2018, 8, 321-326.

61. Mikhaylov, A. Oil and Gas Budget Revenues in Russia after Crisis in 2015. Int. J. Energy Econ. Policy 2019, 9, 375-380.

62. Mikhaylov, A. Cryptocurrency Market Development: Hurst Method. Financ. Theory Pract. 2020, 24, 81-91. [CrossRef]

63. Mikhaylov, A. Geothermal energy development in Iceland. Int. J. Energy Econ. Policy 2020, 10, 31-35. [CrossRef]

64. Mikhaylov, A.; Moiseev, N.; Aleshin, K.; Burkhardt, T. Global climate change and greenhouse effect. Entrep. Sustain. Issues 2020, 7, 2897-2913. [CrossRef]

65. Nie, D.; Panfilova, E.; Samusenkov, V.; Mikhaylov, A. E-Learning Financing Models in Russia for Sustainable Development. Sustainability 2020, 12, 4412. [CrossRef]

66. Nyangarika, A.; Mikhaylov, A.; Tang, B.-J. Correlation of Oil Prices and Gross Domestic Product in Oil Producing Countries. Int. J. Energy Econ. Policy 2018, 8, 42-48.

67. Nyangarika, A.; Mikhaylov, A.; Richter, U. Oil Price Factors: Forecasting on the Base of Modified Auto-regressive Integrated Moving Average Model. Int. J. Energy Econ. Policy 2019, 9, 149-160.

68. Nyangarika, A.; Mikhaylov, A.; Richter, U. Influence Oil Price towards Economic Indicators in Russia. Int. J. Energy Econ. Policy 2019, 9, 123-130. [CrossRef]

69. Yumashev, A.; Ślusarczyk, B.; Kondrashev, S.; Mikhaylov, A. Global Indicators of Sustainable Development: Evaluation of the Influence of the Human Development Index on Consumption and Quality of Energy. Energies 2020, 13, 2768. [CrossRef] 